\title{
Impacts of Climate Change on Human Health and Adaptation Strategies for Nepal
}

\author{
Dhimal $M,{ }^{1}$ Bhusal $\mathrm{CL}^{1}$ \\ ${ }^{1}$ Nepal Health Research Council, Ramshah Path, Kathmandu Nepal
}

\section{BACKGROUND}

One of the greatest threats to the living creatures in the twenty first century is the climate change that is the global variation of earth's climate due to the variability of the forces of nature and human activity. Climate change affects the life supporting systems: atmosphere, hydrosphere and lithosphere and ultimately to biosphere. The International Panel on Climate Change (IPCC) was established by World Meteorological Organization (WMO) and United Nations Environment Programme (UNEP) in1988. The IPCC produced a series of Assessment reports and the most recent publication is the fourth assessment report 2007 which concluded that "Climate change currently contributes to the global burden of disease and premature deaths. At this early stage the effects are small, but are projected to progressively increase in all countries and regions". ${ }^{1}$ Temperature observations in Nepal from 1977-1994 showed a general warming trend with significantly greater warming at higher elevations in the northern part of the country than at lower elevations in the south. ${ }^{2}$ This finding is reinforced by observations by Liu and Chen in 2000 on the other side of the Himalayas on the Tibetan Plateaus. ${ }^{3}$

\section{Impact of Climate Change in Human Health}

Global climate change threatens human health in ways that are numerous and profound. Many parts of the world will experience more extreme events such as droughts, heat waves, altered exposure to infectious disease, and more frequent natural disasters that will put added strain on an already overstressed health system. It will make the Millennium Development Goals that much harder to achieve. The implications of climate change for human health can be grouped into following six main categories $^{1}$

\author{
1. Cardio-respiratory diseases \\ 2. Injuries \\ 3. Nutritional deficiencies /malnutrition \\ 4. Diarrhoeal diseases \\ 5. Vector-borne disease and \\ 6. Psychological stress/diseases
}

The cross-sectional entomological survey conducted in 2006 after first outbreak of dengue in Nepal identified the presence of Aedes aegypti in 5 major urban areas of terai regions bordering with india (Biratnagar, Birgunj, Bharatpur, Tulsipur and Nepalganj) and first record of Aedes aegypti in Kathmandu in 2009. ${ }^{4}$ Previously no Aedes aegypti was recorded in Nepal. The presence of Aedes aegypti in these urban areas may be attributed by climate change.

There is evidence that malaria vector (such as Anopheles fluviatilis) which has traditionally not been found above the elevation of 1500 meters has now been seen in Kashmir, northern part of India and Bhutan at heights of 2000 meters and more. ${ }^{5}$ Now, malaria is highly endemic in 13 districts and endemic in 52 districts of Nepal including few mountain districts. ${ }^{6}$ Though, there are not scientific literature published about the shifting of malaria vector in higher altitude in Nepal, community people and program managers have the experience of emerging mosquitoes and vector borne diseases in higher altitudes in Nepal. One of the reasons for its shifting in higher altitudes and geographical spread might be because of climate change. The increased temperatures due to climate change may create conducive environment to mosquitoes breeding. More research is certainly needed to discern the attribution of climate change. The global warming phenomenon can extend the geographic areas capable of sustaining transmission of vector borne diseases. $^{5}$

Correspondence: Mr. Meghnath Dhimal, Environmental Health Research Unit, Nepal Health Research Council, Ramshah Path, Kathmandu Nepal, Phone: 9841467581, Email: meghd@nhrc.org.np 
Impacts of Climate Change on Human Health and Adaptation Strategies for Nepal

The crops plantation and harvesting seasons has been changed due to shifting monsoon season and the frequency of extreme events such as floods and droughts has increased in recent years in Nepal which may reduce the crop yields, aggravate the problems of hunger and malnutrition, causes injuries as well as Psychological stress/diseases in displaced population from disasters.

\section{Adaptation Strategies}

Adaptation is the prime requisite for vulnerable developing countries like Nepal whose green house gases emission is negligible. ${ }^{7}$ The health impacts of climate change have a number of important characteristics that must be taken into account when framing appropriate adaptation responses. Climate change adaptation strategies must be considered in relation to broader characteristics-such as population growth, poverty, water, sanitation, health care, nutrition and environmental degradation- that influence a population's vulnerability and capacity to adapt. $^{8}$ Following are recommended major adaptation strategies

\section{Strengthening Health System}

There is a need of strengthening health systems capacity to provide protection from climate -related risks and substantially reduction of health systems Green House Gases emissions. Priority should be given for strengthening the existing primary health services including human resource capacity. For example, enhancing the capacity of rapid response team for diseases surveillance, monitoring, response systems and risk communications to reduce the burden of climate sensitive health outcomes is very important.

\section{Awareness, capacity building and promotion of local adaptive knowledge}

Building capacity is an essential step in preparing adaptation strategies. Education, awareness raising and the creation of legal frameworks, institutions and an environment that enables people to take well-informed, long-term, sustainable decisions, all are needed. The awareness programs are needed from policy level to grass root level people about health impacts of climate change.

\section{Coordination among the concerned stakeholders and integration of health impacts of climate change into broader developmental plans and related activities}

Coordination with other sectors and ensuring that health effects are given due importance is very important. For example, coordination with other sectors such as agriculture to address the issues of food security and water sector to deal with the problem of water problem can help reduce their adverse health effects.
The interaction, discussion, media campaign, mediafeature news and public consultation is crucial for the propagation of message of climate change and mainstreaming in development plans. Development of long term multisectoral framework is also very useful to respond the issue effectively.

\section{Promoting Research on Climate Change and Health}

Finally, there is an urgent need for more research to model the health impacts of climate change in specific locations, evaluate approaches to reducing vulnerability, and perform analyses of the cost-effectiveness of different adaptation approaches. Research is required about the possible consequences of climate change, people's perception of those consequences, available adapting options and the benefits of slowing the rate of climate change. It is important to improve understanding of the process of climate change adaptation. This includes gaining better knowledge of the process of adaptation decision -making, roles and responsibilities in adaptation of individuals, communities, nations, institutions and private sector. Of course, research will contribute for framing the best coping strategies and protecting the health of people.

\section{REFERENCES}

1. International Panel on Climate Change. Climate Change 2007: Fourth Assessment Report. UK: Cambridge University Press; 2007.

2. Shrestha AB, Wake CP, Mayewski PA, Dibb JF. Maximum Temperature Trends in the Himalalya and its Vicinity: An Analysis based on temperature records from Nepal for the period 19711994. Journal of Climate. 1999; 12:2775-89.

3. Liu X and B Chen. Climatic Warming in the Tibetan Plateau during Recent Decades. International Journal of Climatology. 2000;20:1729-42.

4. Gautam I, Dhimal M, Shretha SR, Tamrakar AS. First Record of Aedes Aegypti (L.) Vector of Dengue Virus from Kathmandu, Nepal. Journal of Natural History Museum. 2009 :24;156-64.

5. Narain JP. Climate Change and Its Potential Impact on Vector Borne Diseases. Health in South East Asia June 2008 Issue. WHO SEARO; 2008; 14 .

6. Department of Health Services, Ministry of Health and Population, Government of Nepal. Annual Report 2007/2008. Department of Health Services. 2008.

7. Dhimal M. Climate Change and Health: Research Challenges in Vulnerable Mountainous Countries like Nepal. Global Forum for Health Research. Oct 2008; 66-9.

8. World Health Organization, Regional Office for South-East Asia. Climate Change and Human Health in Asia and the Pacific: From evidence to Action: Report of the Regional Workshop, Bali, Indonesia, 10-12 December 2007. World Health Organization; 2007. 